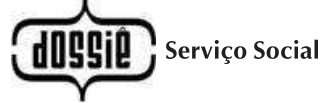

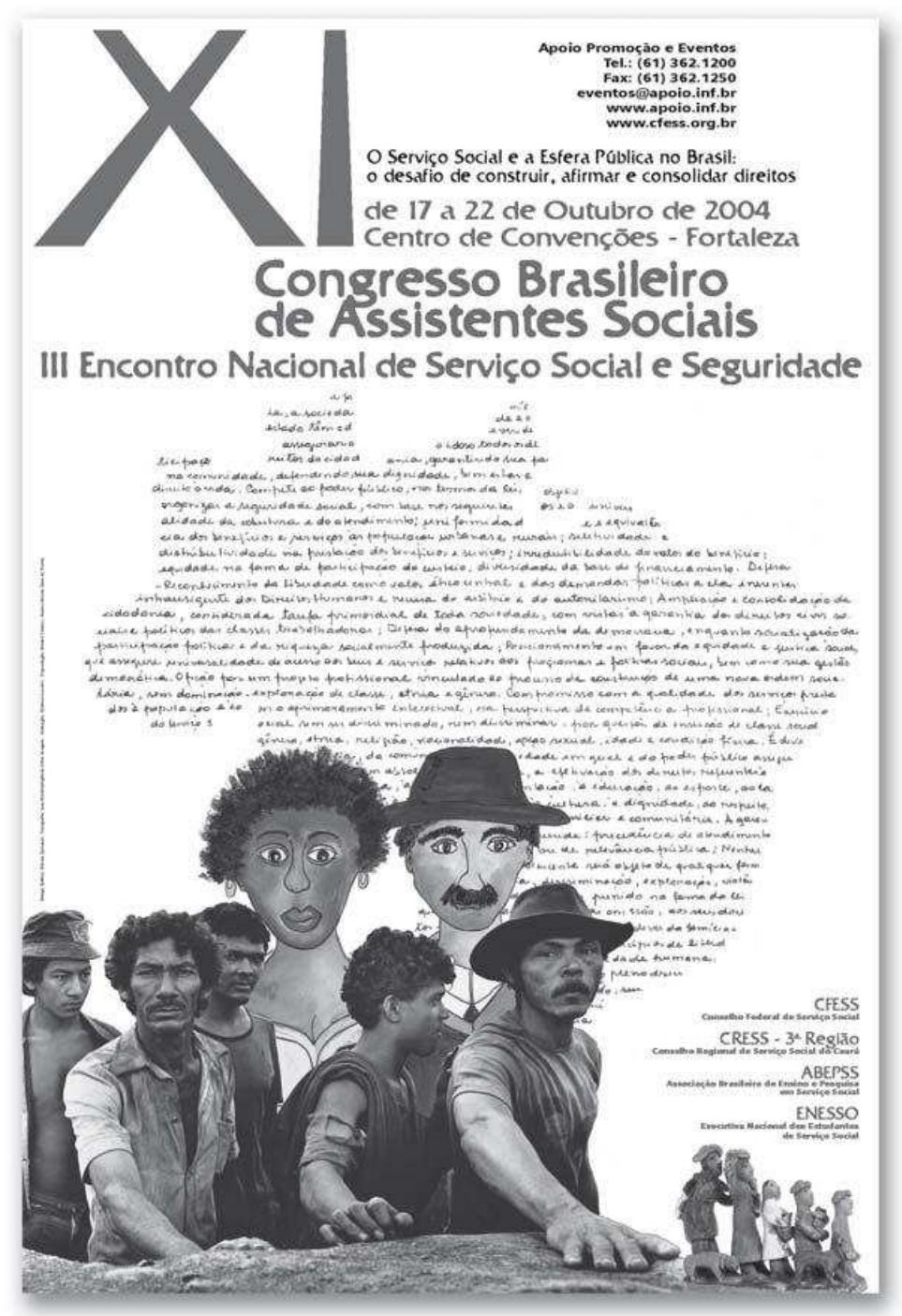

Cartaz do $11^{\circ}$ Congresso Brasileiro de Assistentes Sociais, 2004. 


\title{
Marxismo Gramsciano e Serviço Social: interlocuções mais que necessárias
}

\begin{abstract}
Resumo: $\mathrm{O}$ artigo tem como objetivo resgatar o pensamento de Antonio Gramsci, especialmente sua original abordagem sobre o marxismo definido como filosofia da práxis. Destacam-se as reflexões acerca da relação dialética que o pensador estabelece entre estrutura e superestrutura, objetividade e subjetividade, como dimensões inseparáveis no estudo da sociedade sob o ponto de vista da totalidade e da historicidade, evidenciando-se o nexo orgânico entre as esferas econômica, política e cultural. Aborda-se, finalmente, a relevância da filosofia da práxis e do legado gramsciano no campo dos Fundamentos do Serviço Social, na apreensão das particularidades da prática profissional e sua relação com a totalidade da vida social.

Palavras-chave: Gramsci; marxismo; serviço social.

Abstract: The article aims to rescue the thought of Antonio Gramsci, especially its unique approach to Marxism defined as philosophy of praxis. The highlights are the reflections on the dialectic relationship that the thinker establishes between structure and superstructure, objectivity and subjectivity, while inseparable dimensions in the study of society from the point of view of totality and historicity, demonstrating the organic link between the economic political and cultural sphere. Addresses, finally, the relevance of the philosophy of praxis and the legacy of Gramsci in the field of Social Work Foundations, in the seizure of the peculiarities of professional practice and its relationship with the totality of social life.

Keywords: Gramsci; marxism; social work.
\end{abstract}

\begin{abstract}
*Assistente Social pela Universidade Federal de Santa Catarina (1977), graduação em Serviço Social pela Universidade Federal de Santa Catarina (1977) mestrado em Administração pela Universidade Federal de Santa Catarina (1983), doutorado em Serviço Social pela Pontifícia Universidade Católica de São Paulo (1993 e Pós-doutorado no European University Institute (Florença-2002/03). Professora adjunto II da Universidade Federal de Santa Catarina, Bolsista de Produtividade em Pesquisa do CNPq-Nível 1C. Endereço Postal: Campus Universitário - Centro Sócio Econômico. CEP: 88040-900, Florianópolis, Santa Catarina. Email: ivete.simionatto@pq.cnpq.br
\end{abstract}


nevistg all pautg

\} MARXISMO GRAMSCIANO E SERVIÇO SOCIAL: INTERLOCUÇÕES MAIS QUE NECESSÁRIAS - SIMIONATTO, I. \}

Introdução

Desde os anos 1980, pode-se afirmar que, no âmbito do marxismo, uma das interlocuções mais recorrentes do serviço social tem sido com o pensamento de Antonio Gramsci. Inicialmente buscado como mote para pensar-se o legado da ditadura militar e os processos políticos em curso naquele período, o conjunto da obra gramsciana também contribuiu para a qualificação do processo de renovação do serviço social, com alterações significativas em seu estatuto teórico-político e prático-operativo, fortalecendo o desenvolvimento de uma atitude mais crítica e investigativa. Categorias como Estado ampliado, sociedade civil, hegemonia, filosofia da práxis e classes subalternas foram tomadas como referências na análise dos espaços institucionais e suas contradições, o potencial das forças organizadas da sociedade civil na defesa da democracia, na ampliação da cidadania e na disputa contrahegemônica. Ganhou relevância o debate sobre as ações profissionais vinculadas aos interesses das classes subalternas, suas estratégias de sobrevivência, seus processos de luta e as possibilidades de uma prática comprometida com a construção e o fortalecimento de novos sujeitos políticos. Se, nesse período, ao lado de outros pensadores no eixo da tradição marxista, Gramsci exerceu papel fundamental no processo de renovação do serviço social, com ganhos significativos na interlocução com as Ciências Sociais, possibilitando aos profissionais ultrapassar a posição de "intelectuais subalternos" e consumidores de reflexões de outras áreas, prossegue, na atualidade, como referência imprescindível para se pensar os processos sóciohistóricos em curso.

O exame da literatura publicada dos anos $1980^{1}$ aos dias atuais permite identificar, em diferentes produções do serviço social brasileiro, a frequente abordagem de categorias gramscianas, tomadas como suporte tanto para análises relativas aos processos sociais quanto à especificidade do fazer profissional. Além de referenciado nas produções intelectuais, está presente nos currículos dos cursos de graduação e de pós-graduação, e como recorrência marcante na elaboração de teses e dissertações. Pode-se dizer, assim, que o legado gramsciano persiste suscitando curiosidade e interesse, estimulando interrogações do passado, dos acontecimentos do presente e das situações desafiadoras que têm marcado os dias atuais.

É na trilha dessas indicações que buscamos retomar o pensamento de Gramsci, especialmente em sua original reflexão sobre o marxismo e sua relevância para o serviço social, tanto em relação ao fortalecimento do estatuto teórico da profissão quanto na qualificação das ações prático-interventivas que é desafiado a construir em reposta às manifestações da "questão social". Suas categorias, permeadas de "universalidade", continuam lançando luzes para decifrar as profundas transformações destes tempos em que os fundamentos e pressupostos da hegemonia neoliberal prosseguem imprimindo sua direção ético-política. As reflexões sobre a construção de um projeto de sociedade diverso do capitalismo, pelo qual Gramsci lutou, ainda são fundamentais para pensarmos a realidade contemporânea, em suas

Vale destacar o protagonismo e a contribuição dos trabalhos de Ammann, (1980); Carvalho (1983); Faleiros (1972, 1980); Lima (1982); Serra (1982); Maciel e Cardoso (1989); e mais recentemente: Simionatto (1995); Abreu (2002); Durighetto (2007). 


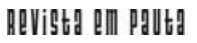

\} MARXISMO GRAMSCIANO E SERVIÇO SOCIAL: INTERLOCUÇÕES MAIS QUE NECESSÁRIAS - SIMIONATTO, I. \}

dimensões histórica, política, econômica e cultural, num movimento de continuidade/ruptura.

\section{A Filosofia da Práxis e o Sentido das Relações entre Estrutura e Superestrutura}

$$
\begin{array}{r}
\text { A lição mais preciosa de Gramsci está no fato de que o seu marxismo é um } \\
\text { marxismo antideterminista e antieconomicista, isto é, voltado a ler a } \\
\text { realidade em toda a sua complexidade, sem jamais separar economia e } \\
\text { política, cultura e necessidades sociais. } \\
\text { Guido Liguori }
\end{array}
$$

Se a perspectiva da totalidade constitui-se na característica central da reflexão marxiana sobre o social, esse mesmo princípio teórico-metodológico é o fio condutor do pensamento de Antonio Gramsci. É sob tal ponto de vista que o pensador italiano analisa a sociedade, buscando desvendar sua multiplicidade de significados, seus antagonismos e contradições. As preocupações com a recuperação de uma visão totalizante da realidade social manifestam-se no conjunto da obra gramsciana, especialmente na centralidade da relação dialética entre economia e política, ou entre estrutura e superestrutura, objetividade e subjetividade. A elaboração teórica de Gramsci remete à necessidade de "conceber a vida e as estruturas sociais" tanto no plano "objetivo" quanto no "subjetivo", ou seja, a "adoção consciente" do que Lukács denomina de "ponto de vista da totalidade", ou a articulação entre "causalidade e teleologia", entre "determinismo e liberdade", entre "momentos de estrutura e momentos de ação" (COUTINHO, 1994, p. 92). A passagem da necessidade à liberdade, da estrutura à superestrutura, "longe de definir uma teoria especulativa da história, determina o presente histórico como tarefa, [...] como formação ético-política" e como projeto revolucionário (TOSEL, 1990, p. 81).

O marxismo, definido por Gramsci como filosofia da práxis, compreende, portanto, o nexo orgânico entre economia e política, entre filosofia, política e cultura. A unidade de tais esferas ocorre mediante o desenvolvimento dialético das contradições entre homem e matéria, ou seja, entre a natureza e as forças produtivas, entre "vontade humana (superestrutura) e estrutura econômica", assim como na política ocorrem as relações entre "o Estado e a sociedade civil" (GRAMSCI, 1999, p.237). A de prevalência do "homem sobre a natureza por meio da técnica" mantém a superioridade dessa, "exaltando-a no trabalho criador" (GRAMSCI, 1999, p. 365). Gramsci não se distancia da tese marxiana de que a gênese histórica da sociedade se situa no ato laboral humano, na práxis técnico-produtiva, na ação humana de transformação da natureza (MARTELLI, 1990), mas considera, também, o modo como os homens organizam-se e participam para reproduzir tais relações ou para superá-las, reforçando o princípio da totalidade social, a interação entre sujeito e objeto, entre consciência e práxis (COUTINHO, 1994). A esfera econômica, nesse sentido, não se reduz à produção de objetos e mercadorias, mas remete, antes de tudo, ao modo como os homens estabelecem suas relações sociais, transformando a si e a própria sociedade. A filosofia da práxis é, portanto, "a síntese dialética" entre a realidade objetiva do meio e a atividade subjetiva dos homens organizados 


\section{Alvistg QIII PaUtg}

\} MARXISMO GRAMSCIANO E SERVIÇO SOCIAL: INTERLOCUÇÕES MAIS QUE NECESSÁRIAS - SIMIONATTO, I. \}

livremente, entre as condições materiais e a intervenção humana, entre estrutura econômica e iniciativa política" (SEMERARO, 2006, p. 34).

Contrapondo-se às teses economicistas, Gramsci entende que a filosofia da práxis não representa especificamente uma "teoria da história" ou das leis econômicas. Ao contrário, a política, a história, a economia e a cultura "se relacionam em unidade orgânica" (GRAMSCI, 1999, p.166). Tanto as indicações de Marx contidas no Prefácio da Contribuição à Crítica da Economia Política quanto as de Lukács em História e consciência de classe, de que a realidade social é melhor compreendida não pelo predomínio dos fatores econômicos, mas antes por meio do princípio da totalidade, estão presentes nas críticas de Gramsci às interpretações economicistas do marxismo, que vicejavam no debate italiano nas primeiras décadas do século XX. Lançando mão do texto de Marx, Gramsci² revela sua preocupação com a análise das condições objetivas e subjetivas, das relações entre estrutura e superestrutura, de um determinado "evento histórico":

A questão da 'objetividade' do conhecimento segundo a filosofia da práxis pode ser elaborada a partir da proposição (contida no prefácio à Critica da economia política) de que 'os homens tornam-se conscientes (do conflito entre as forças materiais de produção) no terreno ideológico' das formas jurídicas, políticas, religiosas, artísticas, filosóficas (GRAMSCI, 1999, p. 209).

O pensador italiano aponta, aqui, a ausência de qualquer economicismo no pensamento de Marx, uma vez que essa consciência "não é limitada ao conflito entre as forças materiais de produção e as relações de produção", pois, "se os homens adquirem consciência de sua posição social e de seus objetivos no terreno das superestruturas, isso significa que entre estrutura e superestrutura existe um nexo necessário e vital" (GRAMSCI, 1999, p. 389). Se, para Marx, a infraestrutura econômica da sociedade contém a superestrutura, esse mesmo pressuposto remete ao conceito gramsciano de "'bloco histórico', no qual, precisamente, as forças materiais são o conteúdo e as ideologias são a forma" (GRAMSCI, 1999, p. 238). Pode-se afirmar, assim, que todas as práticas sociais são mediatizadas "em diversos graus, por todo o tecido social, pelo conjunto das superestruturas" (GRAMSCI, 2000, p. 20). Nas trilhas do "Prefácio de 1859", este é o fio condutor da reflexão de Gramsci em toda a sua obra: o nexo dialético entre estrutura e superestrutura.

A intensa batalha travada para liberar o pensamento de Marx das "incrustações" economicistas e positivistas leva Gramsci ao aprofundamento da função ativa das superestruturas. Na análise da estrutura econômica da sociedade, as expressões "grau de desenvolvimento das forças materiais de produção", "modo de produ-

\footnotetext{
2 "Na produção social da sua vida, os homens contraem determinadas relações, necessárias e independentes da sua vontade, relações de produção, que correspondem a uma determinada fase de desenvolvimento das forças produtivas materiais. O conjunto dessas relações de produção formam a estrutura econômica da sociedade, a base real sobre a qual se levanta a superestrutura jurídica e política, e à qual correspondem determinadas formas sociais de consciência social" (Gramsci, 1999, p. 157). Cf. Marx (1983, p. 24). 


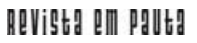

\} MARXISMO GRAMSCIANO E SERVIÇO SOCIAL: INTERLOCUÇÕES MAIS QUE NECESSÁRIAS - SIMIONATTO, I. \}

ção da vida material", "condições econômicas da produção" e similares, na correta interpretação de Gramsci (1999, p. 158), são utilizadas por Marx como "expressões que afirmam certamente ser o desenvolvimento econômico determinado por condições materiais, mas que jamais reduzem estas condições à mera 'metamorfose do instrumento técnico'”. Sobre isso alerta Gramsci (1999, pp. 160-1):

[...] a filosofia da práxis não estuda uma máquina para conhecer e estabelecer a estrutura atômica do material, as propriedades físico-mecânicas dos seus componentes naturais [...], mas enquanto é momento das forças materiais de produção, enquanto é objeto de propriedade de determinadas forças sociais, enquanto expressa uma relação social e esta corresponde a um determinado período histórico [...]. O conjunto das forças materiais de pro-dução é, ao mesmo tempo, uma cristalização de toda a história passada e a base da história presente e futura.

A esfera econômica, em vista disso, não se reduz a "instrumento técnico", mas abarca o "conjunto de relações sociais", uma vez que o trabalho e a técnica configuram-se como as principais formas de relação não só do homem com a natureza, mas também do homem com os outros homens. Relações sociais que se organizam e se complexificam no nexo orgânico entre a infraestrutura econômica e as superestruturas políticas, jurídicas e culturais. Justamente aqui situa-se a teoria da hegemonia, que implica, além da transformação política, a transformação econômica e social. A hegemonia é precisamente o momento em que Estado e economia, estrutura e superestrutura, teoria e prática se relacionam dialeticamente (MARTELLI, 1990). Não é verdadeiro, portanto, que "a filosofia da práxis 'destaque' a estrutura das superestruturas; ao contrário, ela concebe o desenvolvimento das mesmas como intimamente relacionado e necessariamente inter-relativo e recíproco" (GRAMSCI, 1999, p. 369).

A análise das relações entre estrutura e superestrutura constitui-se, para Gramsci, no "problema crucial do materialismo histórico". Para ele, a esfera da superestrutura não pode ser reduzida a uma concepção subjetivista, "própria da filosofia moderna em sua forma mais completa e avançada, se foi dela e como sua superação que nasceu o materialismo histórico" no qual a "teoria das superestruturas" expressa "em linguagem realista e historicista o que a filosofia tradicional expressava em forma especulativa" (GRAMSCI, 1999, p. 131). Desse modo,

[...] a concepção "subjetivista" - após ter servido para criticar a filosofia da transcendência, por um lado, e a metafísica ingênua do senso comum e do materialismo filosófico, por outro - só pode encontrar a sua realização e a sua interpretação historicista na concepção das superestruturas, ao passo que, em sua forma especulativa, ela nada mais é do que romance filosófico (GRAMSCI, 1999, p. 133). 


\section{Alvistg QIII PaUtg}

\} MARXISMO GRAMSCIANO E SERVIÇO SOCIAL: INTERLOCUÇÕES MAIS QUE NECESSÁRIAS - SIMIONATTO, I. \}

Ao criticar incisivamente as concepções economicistas do marxismo que entendem as superestruturas como "simples e débeis 'aparências'", e contra qualquer concepção psicologista e ilusória, Gramsci (1999, pp. 192-3) assevera:

[...] a afirmação de que a "aparência" das superestruturas não seja um fato filosófico de conhecimento, mas somente um ato prático, de polêmica política, é atestado pelo fato de não ser tal afirmação colocada como "universal" mas como algo que diz respeito apenas à determinadas superestruturas" [...] no juízo sobre a "aparência" das superestruturas existe um fato da mesma natureza: um "desengano", um pseudopessimismo etc, que desaparece tão logo se "conquista" o Estado e as superestruturas passam a ser aquelas do próprio mundo intelectual e moral.

Ante essas tendências, que reduziam a filosofia da práxis a uma "escolástica elementar", centradas na classificação abstrata e formal, Gramsci (1999, p. 143) defende a "função e o significado da dialética", os quais "só podem ser concebidos em toda a sua fundamentalidade se a própria filosofia da práxis for concebida como uma filosofia integral e original", que demarca "uma nova fase na história e no desenvolvimento mundial do pensamento, na medida em que supera [...] tanto o idealismo quanto o materialismo tradicionais, expressões das velhas sociedades".

As farpas de Gramsci (2000a, p. 37), contudo, não se dirigem somente às correntes marcadas por um "excesso de economicismo", nas quais "superestimamse as causas mecânicas", reveladas no Tratado de Materialismo Histórico de Bukharin, como também às perspectivas idealistas, permeadas por um "excesso de ideologismo", em que "exalta-se o elemento voluntarista e individual". Suas críticas aqui remetiam à posição "especulativo-teológica" de Benedetto Croce, para o qual a estrutura é entendida como um "deus oculto". Em Gramsci, contrariamente a tais posições, o conceito de estrutura "deve ser compreendido historicamente" como "o conjunto das relações sociais nas quais os homens se movem e atuam, como um conjunto de condições objetivas". Longe de visões especulativas e psicologistas, a subjetividade é aqui desvelada como ato histórico, como "subjetividade histórica de um grupo social', como fato real, [...] como forma de um concreto conteúdo social e o modo de conduzir o conjunto da sociedade a forjar para si uma unidade moral" (GRAMSCI, 1999, p. 297). Observa-se, portanto, no pensamento gramsciano, um significativo esforço na recuperação do papel ativo da subjetividade e sua relação dialética com o processo histórico-social, perspectiva oposta tanto à "intersubjetividade" habermasiana quanto ao "subjetivismo" neoliberal.

Colocando-se radicalmente contra o positivismo e o pensamento conservador, Gramsci afirma que "a atividade crítica", inerente à filosofia da práxis, é a "única possível", notadamente porque busca colocar e resolver de forma crítica todos "os problemas que se apresentam como expressões do desenvolvimento histórico", e não "como um formulário mecânico, que dá a impressão de colocar toda a história no bolso" (GRAMSCI, 1999, p. 146). Como desenvolvimento do hegelianismo, "é uma filosofia liberada (ou que busca liberar-se) de qualquer elemento ideológico 


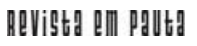

\} MARXISMO GRAMSCIANO E SERVIÇO SOCIAL: INTERLOCUÇÕES MAIS QUE NECESSÁRIAS - SIMIONATTO, I. \}

unilateral e fanático", representando a tomada de "consciência plena das contradições". Nesse processo, "o próprio filósofo, entendido individualmente ou como grupo social global, não só compreende as contradições, mas coloca a si mesmo como elemento de contradição e eleva este elemento a princípio de conhecimento e, consequentemente, de ação" (GRAMSCI, 1999, p. 204). Essa é, aos olhos de Gramsci (1999, p. 368), uma batalha entre diferentes "maneiras de ver a realidade", uma disputa entre visões de mundo e, nesse embate, "a filosofia da práxis pretende justificar a historicidade das filosofias, não mediante princípios gerais, mas através da história concreta, da historicidade dialética".

Pode-se dizer que não só a filosofia da práxis não exclui a história ético-política, como, ao contrário, sua mais recente fase de desenvolvimento consiste precisamente na reivindicação do momento da hegemonia como essencial à sua concepção estatal e à "valorização" do fato cultural, da atividade cultural, de uma frente cultural como necessária, ao lado das frentes meramente econômicas e políticas (GRAMSCI, 1999, p. 295). ${ }^{3}$

A relação estrutura/superestrutura aparece, ainda, em vários momentos da pesquisa gramsciana, notadamente nas elaborações a respeito do Estado, da sociedade civil, da hegemonia, das classes subalternas, do indivíduo. Uma das mais significativas contribuições diz respeito à política, sintetizada no termo "catarse", em que ocorre "a passagem do momento meramente econômico (ou egoístico-passional) ao momento ético-político, isto é, a elaboração superior da estrutura em superestrutura na consciência dos homens", ou, ainda, "a passagem do 'objetivo ao subjetivo', e da 'necessidade à liberdade"' (GRAMSCI, 1999, p. 314). O momento catártico seria, então, "o ponto de partida da filosofia da práxis", do "desenvolvimento dialético" entre estrutura e superestrutura, entre objetividade e subjetividade, "em meio de liberdade, em instrumento para criar uma nova forma ético-política, em origem de novas iniciativas". Aqui, "a teoria das superestruturas é a tradução da concepção subjetiva da realidade em termos de historicismo realista" (GRAMSCI, 1999, p. 315) e a filosofia da práxis "é o historicismo absoluto, ${ }^{4}$ a mundialização e terrenalidade absoluta do pensamento, um humanismo absoluto da história" (GRAMSCl, 1999, p. 155). Contra as expressões do "espírito", o historicismo gramsciano, desvinculado de qualquer resíduo de transcendência, busca afirmar a imanência do marxismo, colocando acento na historicidade dos fenômenos sociais e na expressão das lutas e conflitos sociais (BIANCHI, 2008). Em outros termos, falar de historicismo, para Gramsci, significa aprofundar o sentido da historicidade e da

\footnotetext{
${ }^{3}$ A valorização da cultura no pensamento de Gramsci distancia-se claramente das perspectivas pós-modernas e dos estudos antropológicos, sendo definida como elemento determinante na análise do social. Há uma clara diferença, portanto, entre a perspectiva analítica do culturalismo e do pós-modernismo, limitados à defesa da identidade e dos direitos particulares, e a visão revolucionária de Gramsci.

${ }^{4}$ Embora o termo tenha sido utilizado por Benedetto Croce, Gramsci distancia-se da visão idealista do filósofo napolitano, não deslocando-o da dimensão teórica do marxismo.
}

EM PAUTA, Rio de Janeiro (RJ), v. 9, n. 27, p. 17-33, Jul. 2011 


\section{Alvistg QIII PaUtg}

\} MARXISMO GRAMSCIANO E SERVIÇO SOCIAL: INTERLOCUÇÕES MAIS QUE NECESSÁRIAS - SIMIONATTO, I. \}

totalidade. Pressupõe entendê-lo como unidade dialética entre filosofia, história, política e economia, teoria e prática, objetividade e subjetividade, ação e pensamento.

Os "fatos da superestrutura", contudo, não "devem ser abandonados a si mesmos, a seu desenvolvimento espontâneo, a uma germinação casual e esporádica". A superestrutura não se reduz a um "ato mental" ou ao "reino das ideias autogeradas", mas abarca, também, a esfera das estruturas materiais. Ao afirmar o plano das ideias, o pensamento gramsciano não pode reduzir-se a "uma exaltação idealista das restrições materiais historicamente dadas" (GRAMSCl, 2000a, p. 28). Ao contrário, Gramsci jamais deixou de identificar os antagonismos estruturais do modo de produção capitalista, bem como seus parâmetros de dominação e exploração no contexto da ordem econômica burguesa. Não há em sua obra uma rejeição da economia ou da esfera estrutural, mas um diagnóstico das novas determinações do capitalismo, dos problemas em jogo e da busca de soluções para enfrentá-los. Tendo em vista as posições acima, não poder-se-ia atribuir ao pensador italiano uma interpretação reducionista e idealista, conforme pontua Norberto Bobbio (1976). Gramsci não é o "teórico das superestruturas", o que se pode comprovar em várias passagens dos Cadernos.
A formulação do movimento do livre-câmbio baseia-se num erro teórico cuja origem prática não é difícil identificar, ou seja, baseia-se na distinção entre sociedade política e socie- dade civil, que de distinção metodológica é transformada e apresentada como distinção orgânica. Assim, afirma-se que a atividade econômica é própria da sociedade civil e que o Es- tado não deve intervir em sua regulamentação. Mas, dado que sociedade civil e Estado se identificam na realidade dos fatos, deve-se estabelecer que também o liberismo é uma "re- gulamentação" de caráter estatal, introduzida e mantida por via legislativa coercitiva: é um fato de vontade consciente dos próprios fins, e não a expressão espontânea, automática, do fato econômico (GRAMSCI, 2000a, p. 47).

A sociedade civil aqui aparece, também, como o lugar dos interesses materiais e econômicos, da propriedade privada ou do "mundo dos negócios" (BIANCHI, 2008), como poder-se-ia denominar no capitalismo contemporâneo. Igualmente, no Caderno 13, ao falar da reforma intelectual e moral (forma da revolução no Ocidente), Gramsci indaga: "pode haver reforma intelectual e moral, ou seja, elevação civil das camadas mais baixas da sociedade, sem uma anterior reforma econômica e uma modificação na posição social e no mundo econômico?". Em vista disso, "uma reforma intelectual e moral não pode deixar de estar ligada a um programa de reforma econômica", ou, "mais precisamente, o programa de reforma econômica é exatamente o modo concreto através do qual se apresenta toda reforma intelectual e moral" (GRAMSCI, 2000a, p. 19). Segundo Gramsci (2000a, p. 224), "não pode existir igualdade política completa e perfeita sem igualdade econômica". 


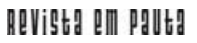

\} MARXISMO GRAMSCIANO E SERVIÇO SOCIAL: INTERLOCUÇÕES MAIS QUE NECESSÁRIAS - SIMIONATTO, I. \}

Outra passagem dos Cadernos, quando Gramsci fornece uma metodologia de análise de conjuntura, indica, de forma bastante explícita, que a esfera da política, ou seja, a análise das relações de poder, implica partir sempre "das bases econômicas sobre as quais se desenvolve a ação política", ou seja, das relações sociais de produção (COUTINHO, 1994, p. 111). Ao abordar os "diversos momentos ou graus" na "relação de força", o pensador indica que o primeiro nível compreende a análise da "relação de forças sociais estritamente ligada à estrutura, objetiva, independente da vontade dos homens, que pode ser mensurada com os sistemas das ciências exatas ou físicas" (GRAMSCI, 2000a, p. 40). O conhecimento das estruturas econômicas e "o desenvolvimento das forças materiais de produção" permitem "estudar se existem na sociedade as condições necessárias e suficientes para sua transformação" (GRAMSCl, 2000a, p. 40). Num segundo momento, denominado "relação das forças políticas", Gramsci analisa o modo de organização das classes e grupos sociais, seu grau de consciência e as possibilidades concretas de forjar, "além da unicidade dos fins econômicos e políticos, também a unidade intelectual e moral" (GRAMSCI, 2000a, p. 41). A análise das esferas política e econômica é, portanto, remetida à totalidade sócio-histórica, pois a inovação fundamental da filosofia da práxis "introduzida na ciência da política e da história é a demonstração de que não existe uma 'natureza humana' abstrata, fixa e imutável [...], mas que a natureza humana é o conjunto das relações sociais historicamente determinadas" (GRAMSCI, 2000a, p.56).

Além disso, importa sublinhar que a "filigrana" das páginas dos Cadernos é a compreensão da filosofia da práxis como ação revolucionária. Retomando as Teses sobre Feuerbach - "os filósofos interpretaram o mundo, mas trata-se agora de transformá-lo" -, Gramsci afirma que a filosofia da práxis "deve se tornar política para tornar-se verdadeira, para continuar a ser filosofia, que a 'tranquila teoria' deve ser 'realizada praticamente', deve fazer-se 'realidade efetiva'", ou seja, manter a "unidade entre teoria e prática" (GRAMSCI, 1999, p. 189). Observa-se, portanto, a preocupação não somente de uma "investigação cognoscitiva do real, mas também a tarefa de elaborar uma linha de ação política que modifique as relações de força, reabra o confronto hegemônico", provocando um processo revolucionário (LIGUORI, 2007 , p. 107). Suas preocupações estão voltadas, prioritariamente, ao desvendamento das novas determinações da hegemonia burguesa nos marcos do capitalismo mono-polista e das expressões na esfera das superestruturas, entendendoas, evidentemente, conforme já salientamos, no seu nexo orgânico com a infraestrutura econômica.

De que forma, então, essa perspectiva teórico-política pode oferecer elementos para se pensar práticas profissionais particulares como o serviço social?

\section{2 - Interlocução com o Serviço Social}

Mesmo considerando que a teoria marxista gramsciana tem como horizonte a construção de uma nova ordem social por meio de um processo revolucionário, é imperioso reconhecer o significativo arco de mediações que oferece para pensar as ciências sociais particulares e os projetos profissionais, de forma a contribuírem para a efetivação da práxis social. 


\section{Alvistg QIII PaUtg}

\} MARXISMO GRAMSCIANO E SERVIÇO SOCIAL: INTERLOCUÇÕES MAIS QUE NECESSÁRIAS - SIMIONATTO, I. \}

Dentre os pensadores marxistas, Gramsci é, indiscutivelmente, o que mais se debruçou sobre a análise de temas hoje largamente incorporados ao debate de várias áreas, "mas sem jamais perder de vista a dimensão filosófica da totalidade" (COUTINHO, 1994, p. 113). É a partir desse patamar que podemos recobrar sua atualidade e perfilhar sua rica e instigante contribuição ao campo do serviço social. Assim, mesmo não sendo uma ciência, mas uma prática profissional e uma área de conhecimento, o serviço social recebe do legado categorial gramsciano elementos imprescindíveis para pensar a profissão e as esferas com as quais trabalha, a partir de um "tratamento crítico-dialético", sob um ângulo totalizante. Contribui, desse modo, no conhecimento e na desfetichização dos objetos ou das realidades particulares nas quais atua, superando sua aparente neutralidade e (re)construindo-as por meio de sua vinculação com a totalidade da vida social (COUTINHO, 1994). Parafraseando Mészáros (2004, pp. 500-1), o serviço social atua nas "microestruturas sociais", mas essas "trazem as marcas indeléveis da macroestrutura a que pertencem; e vice-versa, a macroestrutura de uma determinada formação socioeconômica representa a configuração geral de seus componentes multifacetados".

A compreensão do serviço social como "uma especialização do trabalho, parte das relações sociais que fundam a sociedade do capital" (IAMAMOTO, 2009, p. 25). O seu significado social só pode ser desvendado no âmbito do processo de produção e reprodução das relações sociais (IAMAMOTO, 2007), e, portanto, remete à análise das condições objetivas e subjetivas, da "vida material e espiritual", envolvendo tanto a satisfação das necessidades materiais quanto a ação do sujeito e de suas lutas. A prática profissional encontra-se, assim, organicamente vinculada "às configurações estruturais e conjunturais da 'questão social' e às formas históricas de seu enfrentamento, que são permeadas pela ação dos trabalhadores, do capital e do Estado" (ABESS/CEDEPSS, 1996, p. 154).

Se as ações profissionais do serviço social situam-se "predominantemente no terreno político e ideológico, com refrações nas condições materiais de existência dos sujeitos" (IAMAMOTO, 2007, p. 418), é também nesta esfera que as classes subalternas têm possibilidades de construir novas subjetividades e estratégias políticas voltadas tanto à transformação da esfera material como, também, à construção de uma hegemonia cultural e política, necessária à emergência de um novo projeto societário. Como prática profissional permeada pela segmentação da divisão social do trabalho, própria da sociedade capitalista, o serviço social, no diálogo com o rico universo categorial presente na obra de Gramsci, encontra suportes teóricometodológicos essenciais e imprescindíveis para apreender as particularidades das ações profissionais e remetê-las à totalidade da vida social. Tentemos precisar alguns pontos dessa interlocução.

Na esfera da subjetividade, ao apreender as mudanças introduzidas pelo capitalismo desenvolvido, Gramsci analisa criticamente suas consequências, especialmente nos modos de pensar das camadas subalternas, cuja conduta tornava-se cada vez menos "independente e autônoma" e mais "submissa e subordinada" ao pensamento das elites conservadoras. Esse eixo de reflexão também oferece elementos para analisar as intensas transformações sócio-econômicas e políticas ocorridas nas últimas décadas no âmbito das relações entre capital e trabalho, Estado e 


\section{heVistg QIII PaUtd}

\} MARXISMO GRAMSCIANO E SERVIÇO SOCIAL: INTERLOCUÇÕES MAIS QUE NECESSÁRIAS - SIMIONATTO, I. \}

sociedade, cultura e ideologia, expressões do projeto neoliberal e suas formas ideológicas cada vez mais refinadas de submissão e subalternização. As estratégias de domínio no campo econômico, necessárias à reestruturação do capital, face à sua crise estrutural, que se estende desde os anos 1970 até os dias atuais, impõem, ao mesmo tempo, a necessidade de socialização de novos valores e regras de comportamento, de modo a atender tanto a esfera da produção quanto a da reprodução social, envolvendo as diversas dimensões da vida social. Nesse sentido, um conjunto de fatores nos campos objetivo e subjetivo redefine a correlação de forças entre as classes sociais e, consequentemente, os projetos sócio-políticos mais amplos, já que o controle do capital não incide somente na extração da mais-valia, mas, fundamentalmente, no consentimento e na adesão das classes à nova ideologia (SIMIONATTO, 2003). Portanto, se a hegemonia é "algo que opera não apenas sobre a estrutura econômica e sobre a organização política da sociedade, mas também sobre o modo de pensar, sobre as orientações ideológicas e sobre os modos de conhecer" (GRUPPI, 1978), Gramsci destaca-se, certamente, como um dos pensadores privilegiados que, na atualidade, auxilia-nos no desvendamento dos processos que permeiam tanto as relações de dominação e exploração na esfera econômica como a formação de novos padrões culturais e formas de pensar.

No plano ideológico, a visão de mundo da classe economicamente dominante tem saturado a sociedade, imprimindo sua direção ético-política, colocando-se "a si mesma como um organismo em contínuo movimento, capaz de absorver toda a sociedade, assimilando-a a seu nível cultural e econômico" (GRAMSCI, 2000a, p.271). Se as massas modernas não conseguem assumir o desafio de modificar esse processo qualitativamente, se permanecem impotentes, as "revoluções passivas" e as "contrarrevoluções" apresentam-se como o horizonte universal negativo, isto é, uma universalização econômico-corporativa, também hoje dominante (TOSEL, 1990, p. 86). Criticar e contrapor-se a esse modo de pensar e compreender de que forma perpassam as visões de mundo das classes subalternas, por meio da religião, do folclore e do senso comum - manifestações da consciência ideológica -, são pontos essenciais à criação de um novo "senso comum crítico", alicerce para o rompimento com as condições de subalternidade.

Mesmo longa, vale citar a passagem abaixo, na qual Gramsci (2000, 78-9), por meio de uma reflexão minuciosa, identifica como os modos de pensar se difundem por toda a sociedade:

Um estudo de como se organiza de fato a estrutura ideológica de uma classe dominante, isto é, a organização material voltada para manter, defender e desenvolver a 'frente' teórica ou ideológica [...]. A imprensa é a parte mais dinâmica dessa estrutura ideológica, mas não a única: tudo o que influi ou pode influir sobre a opinião pública, direta ou indiretamente, faz parte dessa estrutura. Dela fazem parte: as bibliotecas, as escolas, os círculos e os clubes de variado tipo, até a arquitetura, a disposição e o nome das ruas [...]. O que se pode contrapor, por parte de uma classe inovadora, a este complexo formidável 


\section{Alvistg QIII PaUtg}

\} MARXISMO GRAMSCIANO E SERVIÇO SOCIAL: INTERLOCUÇÕES MAIS QUE NECESSÁRIAS - SIMIONATTO, I. \}

de trincheiras e fortificações da classe dominante? O espírito de cisão, isto é, a conquista progressiva da consciência da própria personalidade histórica, espírito de cisão que deve tender a se ampliar da classe protagonista às classes aliadas potenciais: tudo isso requer um complexo trabalho ideológico.

Pode-se observar, aqui, que a luta por uma nova hegemonia não se reduz à disputa entre "concepções de mundo", mas "é também a luta dos aparelhos que funcionam como suportes materiais dessas ideologias, organizando-as e difundindoas" (BIANCHI, 2008, p.179). Além disso, a "luta pela hegemonia é luta de ideologias", e "a luta ideológica não é só 'batalha das ideias'; estas ideias têm uma 'estrutura material', articulam-se em aparelhos" (LIGUORI, 2007 p. 90) . À vista disso, considerando que o assistente social exerce um papel importante na difusão de uma nova concepção de mundo, sua atuação prática abarca uma dimensão educativa, essencial para elaborações inovadoras e antagônicas aos velhos modos de pensar (GRAMSCI, 1999), que não desapareceram, mas antes manifestam-se e rearticulamse sob uma nova roupagem. O profissional domina um universo de valores que mobiliza na atuação junto às classes subalternas, podendo imprimir direções diversas a partir da linguagem, ou, no dizer de Gramsci, da "tradutibilidade". Embora o termo remeta à análise de contextos históricos mais amplos, Gramsci (1999, p. 185) o utiliza também como expressão das "várias linguagens filosóficas e científicas", como elemento que traduz diferentes concepções de mundo. Se, para Gramsci, o político é um "homem de ação", essa efetua-se quase que exclusivamente por meio da linguagem: "intervém nas reuniões, faz comícios, escreve documentos e ensaios, emite diretrizes, e ainda lê, escuta, conversa etc." (SCHIRRU, 2010, p. 320). Esse mesmo fio analítico pode ser remetido ao profissional de serviço social na efetivação de seu fazer, e no conjunto de elementos que necessita mobilizar para dar concretude à ação. Assim, pensar uma prática profissional é pensar igualmente os elementos constitutivos da linguagem ou o universo de valores mobilizados, que tanto podem ser progressistas como conservadores. Implica não apenas o domínio formal de um conjunto de técnicas, mas também de um constructo teórico e de um ideário éticopolítico, determinantes para se trabalhar elementos simbólicos, ideológicos, ideias e valores presentes na esfera cotidiana das classes subalternas, constituindo-se em momento essencial à consolidação da alienação ou desalienação, à modificação ou à cristalização de modos de pensar e de visões de mundo. Nessa perspectiva, vale esclarecer que o valor atribuído à linguagem por Gramsci não se confunde com o significado habermasiano "do mundo da vida".

Gramsci insiste que a concepção de mundo manifestada nas palavras e na ação, ainda que embrionária, descontínua e ocasional, contém uma ação política. É por essa razão "que não se pode separar a filosofia da política; ao contrário, podese demonstrar que a escolha e a crítica de uma concepção do mundo são, também elas, fatos políticos" (GRAMSCI, 1999, p. 97). Para o serviço social, a compreensão desse patamar inicial nos espaços sócio-profissionais permite trabalhar o "contraste entre o pensar e o agir", seja de indivíduos ou grupos, entendendo-os como "expressão de contrastes mais profundos de natureza histórico-social" (GRAMSCI, 1999, p. 


\section{heVistg QIII PaUtd}

\} MARXISMO GRAMSCIANO E SERVIÇO SOCIAL: INTERLOCUÇÕES MAIS QUE NECESSÁRIAS - SIMIONATTO, I. \}

97), reconstruindo as "expressões da linguagem comum" e imprimindo à ação "uma direção consciente" (GRAMSCI, 1999, p.98). Somente por meio de um grande esforço de reflexão, de "disciplina intelectual", os indivíduos poderão "exprimir uma identidade de pensamento e de práxis em sentido forte", o que se efetiva quando elaboram, primeiro individual depois coletivamente, a própria concepção de mundo (BADALONI, 1990, p. 10). Mas isso não ocorre espontaneamente, como lembra Gramsci (1999, p. 104), ao observar que não há como uma "massa humana" distinguir-se ou tornar-se independente "para si" sem "organizar-se (em sentido lato)". Por outro lado, "não existe organização sem intelectuais, isto é, sem organizadores e dirigentes, ou seja, sem o aspecto teórico da ligação teoria-prática".

Ao recuperar o papel ativo do sujeito na história, Gramsci (1999, p. 406) indica que "o homem não se define como indivíduo, psicológica e especulativamente", mas "como o conjunto de relações sociais [...], o conjunto das suas condições de vida". O homem é concebido "como um bloco histórico" atravessado por elementos "subjetivos e individuais", assim como por "elementos de massa e objetivos ou materiais, com as quais o indivíduo está em relação ativa". Mas reconhecer "a existência de condições objetivas, ou possibilidade, ou liberdade - ainda não é suficiente: é necessário 'conhecê-las' e saber utilizá-las. Querer utilizá-las". Trilhar esse caminho implica, para Gramsci (1999, p. 406): 1) imprimir "uma direção determinada e concreta ("racional") ao próprio impulso vital ou vontade"; 2) identificar "os meios que tornam essa vontade concreta e determinada, e não ar-bitrária"; 3) contribuir "para modificar o conjunto das condições concretas que rea-lizam essa vontade, na medida de suas próprias forças e da maneira mais frutífera".

A superação da subalternidade impregnada de senso comum realiza-se, portanto, quando se parte "das contradições materiais da vida prática", levando em conta as demandas que o senso comum expressa, "o nível de consciência das massas que permita às classes subalternas uma nova consciência de si [...] uma nova subjetividade e, portanto, um novo 'espírito de cisão'" (LIGUORI, 2007, p. 123). Assim, o momento da esfera das necessidades também implica o momento ético-político, ou seja, sua reelaboração em um momento superior. As forças ainda em estágio primitivo, em sua expressão corporativa "se transformam, se metabolizam como ético-políticas" (TOSEL, 1990, p. 83).

Reside aqui a razão da grande importância conferida por Gramsci ao estudo do folclore, da religião, do senso comum, das formas de organização das classes subalternas e à elaboração teórico-prática de um novo projeto construído a partir das "vontades associadas" (GRAMSCI, 2000a). A negação da subalternidade parte "necessariamente das condições reais existentes, das contradições do real, dos fragmentos que compõem a ideologia subalterna, dos impulsos de rebeldia dos dominados" (DEL ROIO, 2007, p. 8).

$\mathrm{Na}$ tessitura do pensamento gramsciano, as reflexões sobre a subalternidade aparecem dialeticamente interligadas ao Estado, à sociedade civil, à hegemonia, à ideologia, à cultura e à filosofia da práxis. No estudo das classes subalternas, Gramsci (2002, p. 140) ancora sua proposta em uma série de mediações, tais como: suas relações com o "desenvolvimento das transformações econômicas"; a "adesão ativa ou passiva às formações políticas dominantes"; as lutas travadas a fim de "influir 


\section{Alvistg QIII PaUtg}

\} MARXISMO GRAMSCIANO E SERVIÇO SOCIAL: INTERLOCUÇÕES MAIS QUE NECESSÁRIAS - SIMIONATTO, I. \}

sobre os programas dessas formações para impor reivindicações próprias"; a formação de "novos partidos dos grupos dominantes, para manter o consenso e o controle dos grupos sociais subalternos"; a caracterização das reivindicações dos grupos subalternos; e "as formas que afirmam a autonomia". Tal abordagem oferece ao serviço social suporte e indicações substanciais ao estudo das classes subalternas, ao desvelamento do seu modo de vida e suas determinações no contexto da produção e reprodução das relações sociais.

No que concerne ao Estado, Gramsci o concebe em seu sentido orgânico, formado pela sociedade política e pela sociedade civil, e, portanto, como espaço contraditório, arena de disputas e "momento ineludível na luta pela hegemonia" (LIGUORI, 2003, p. 184). Em toda a sua ampla reflexão sobre as novas determinações do capitalismo monopolista, Gramsci (2000a, p. 42) define a vida estatal "como uma contínua formação e superação de equilíbrios instáveis [...] entre os interesses do grupo fundamental e os interesses dos grupos subordinados", o que remete ao embate entre as classe sociais e à incorporação dos interesses dos grupos subalternos. No entanto, na realidade contemporânea, o Estado burguês tem ampliado seu campo de ação, mediante o atendimento de interesses econômico-corporativos, assimilando em seu interior diferentes camadas de classe, apostando na desestruturação das lutas das classes subalternas e na desestabilização das forças historicamente progressistas. A perda de sua centralidade e a reestruturação de funções e papéis fortalecem uma cultura política que substitui a relação estatal pela livre regulação do mercado. Sob esta ótica, eliminam-se os antagonismos de classe, e a burguesia "não só justifica e mantém o seu domínio, mas consegue obter o consenso ativo dos governados" (GRAMSCl, 2000a, p. 331), encaminhando, a seu modo, uma verdadeira "reforma intelectual e moral". Esse processo reveste-se de um grande poder desmobilizador, visto que o Estado bloqueia as iniciativas da sociedade civil na articulação de interesses e propostas voltados à luta pela superação entre "governantes e governados", dirigentes e dirigidos. Esse agir do Estado, associado às intensas formas de despolitização da sociedade civil, reforça a fragmentação social das classes subalternas e dos espaços de participação, criando um novo "senso comum", "do qual são expelidos a política, a participação, a vida em relação aos outros, o sentido de comunidade" (LIGUORI, 2003, p. 186). Esse eixo de reflexão remete às preocupações contemporâneas do serviço social a respeito das mudanças operadas na esfera estatal com o crescente repasse de várias funções à sociedade civil, especialmente às organizações articuladas em torno do Terceiro Setor (ONGs, voluntariado, filantropia), na execução das políticas sociais. A atual visão maniqueísta de Estado e de sociedade civil, associada à despolitização política e à perda do protagonismo dos institutos coletivos classistas, remete à importância da concepção gramsciana de sociedade civil - terreno de luta de classes, de disputa contra-hegemônica e de construção de novos Estados.

Nesse campo, vale salientar a relevância das ações profissionais desenvolvidas em organizações da sociedade civil, vinculadas aos interesses das classes e camadas subalternas, junto aos movimentos sociais e populares, em suas formas de organização, contestação e resistência, bem como na luta pela defesa de direitos conquistados. Esses constituem-se em espaços de democratização e aprendizado po- 


\section{heVistg QIII PaUtd}

\} MARXISMO GRAMSCIANO E SERVIÇO SOCIAL: INTERLOCUÇÕES MAIS QUE NECESSÁRIAS - SIMIONATTO, I. \}

líticos, "imprescindíveis para que seus sujeitos enfrentem a grande política" (NETTO, 2004, p. 78), convergindo as vontades particulares às instâncias universalizadoras da política, ou seja, à perspectiva da totalidade social. Em outras palavras, importa pensar, a partir do fio teórico-analítico gramsciano, a particularidade do projeto profissional e sua vinculação aos projetos societários. Cabe observar que, se para Gramsci as lutas travadas no âmbito da sociedade civil não se reduzem à conquista de direitos de cidadania e à expansão do debate democrático, sua defesa intransigente tem implicações concretas na contraposição ao projeto burguês, na diminuição das barreiras coercitivas do Estado e, inegavelmente, no fortalecimento da práxis política coletiva com vistas à construção de uma nova hegemonia.

As instigantes reflexões de Gramsci, especialmente "no plano do método" e de seu rico instrumental de análise, oferecem, portanto, possibilidades inovadoras na apreensão da prática profissional "em suas dimensões de universalidade, particularidade e singularidade" (ABEPSS, 1996), o que exige um "rigoroso trato teórico, histórico e metodológico da realidade social e do Serviço Social" para a "compreensão dos problemas e desafios com os quais o profissional se defronta no universo da produção e reprodução da vida social". Aprofundar e aperfeiçoar o conhecimento dessa realidade impõe-se como condição essencial na luta pela transformação social, mediante a "crítica real da racionalidade e historicidade dos modos de pensar" (GRAMSCl, 1999, p. 111), das "contradições materiais da vida prática", das condições objetivas, das necessidades históricas (LIGUORI, 2007) e das formas de resistência forjadas no cotidiano das classes subalternizadas, como possibilidade de enfrentamento à hegemonia capitalista contemporânea, o que poderá ocorrer por meio da filosofia da práxis, ou seja, do marxismo. 


\section{Alvistg QIII PaUtg}

\} MARXISMO GRAMSCIANO E SERVIÇO SOCIAL: INTERLOCUÇÕES MAIS QUE NECESSÁRIAS - SIMIONATTO, I. \}

\section{Referências}

ABESS/CEDEPSS. "Proposta básica para o projeto de formação profissional". Serviço Social \& Sociedade, n. 50, São Paulo: Cortez, abril, 1996, pp.143-171.

ABEPSS. Diretrizes gerais para o curso de Serviço Social. Recife, 1996. Disponível em: http://www.abepss.org.br/briefing/documentos/Lei_de_Diretrizes_Curriculares 1996. Acesso em: nov. 2010.

ABREU, M. M. Serviço Social e organização da cultura: perfis pedagógicos da prática profissional. São Paulo: Cortez, 2002.

AMMANN, S. B. Ideologia do desenvolvimento de comunidade no Brasil. São Paulo: Cortez, 1980.

BADALONI, N. "Marxismo e teoria della politica in Antonio Gramsci". In: BADALONI, N. et al. (orgs.). Gramsci e il marxismo contemporaneo. Roma: Riuniti, 1990, pp. 7-23.

BEHRING, E. R. e BOSCHETTI, I. Política Social: fundamentos e história. São Paulo: Cortez, 2006.

BIANCHI, A. O laboratório de Gramsci: filosofia, história e política. São Paulo: Alameda, 2008.

CARVALHO, A. M. P. A questão da transformação e o trabalho social. São Paulo: Cortez, 1983.

COUTINHO, C. N. Marxismo e Política: a dualidade de poderes e outros ensaios. São Paulo: Cortez, 1994.

DEL ROIO, M. "Gramsci e a emancipação do subalterno". Revista de sociologia e política, n. 29. Curitiba: UFPR, nov. 2007, pp. 63-78.

DURIGUETTO, Maria Lúcia. Sociedade civil e democracia: um debate necessário. São Paulo: Cortez, 2007.

FALEIROS, V. P. Trabajo social: ideologia y método. Buenos Aires: Ecro, 1972. - A política social do Estado capitalista. São Paulo: Cortez, 1980.

GRAMSCI, A. Cadernos do cárcere. Tradução de Carlos Nelson Coutinho com a colaboração de Luiz Sergio Henriques e Marco Aurélio Nogueira. Rio de Janeiro: Editora Civilização Brasileira, v. 1, 1999/ v. 2, 2000/ v. 3, 2000a/ v. 5, 2002.

GRUPPI, L. O conceito de hegemonia em Gramsci. 2 ed. Rio de Janeiro: Graal, 1978.

IAMAMOTO, M. Serviço social em tempo de capital fetiche. São Paulo: Cortez, 2007.

"O Serviço Social na cena contemporânea". Serviço Social: direitos sociais e competências profissionais. Brasília: CFESS, 2009, pp. 15-45.

LIGUORI, G. "Estado e sociedade civil: entender Gramsci para entender a realidade". In: COUTINHO, C. N. e TEIXEIRA, A de P (orgs.). Ler Gramsci, entender a realidade. Rio de Janeiro: Civilização Brasileira, 2003, pp. 173-188.

Roteiros para Gramsci. Rio de Janeiro: Editora da UFRJ, 2007.

LIMA, M. H. de A. Serviço Social e Sociedade Brasileira. São Paulo: Cortez, 1987. 


\section{heVistg QIII PaUtd}

\} MARXISMO GRAMSCIANO E SERVIÇO SOCIAL: INTERLOCUÇÕES MAIS QUE NECESSÁRIAS - SIMIONATTO, I. \}

MACIEL, M. e CARDOSO, F. G. "Metodologia do serviço social: a práxis como base conceitual". Cadernos ABESS. São Paulo: Cortez, n. 3, 1989.

MARTELLI, M. Gramsci. Per una teoria marxista della sggettività. In: BADALONI, N. et al. (org.). Gramsci e il marxismo contemporaneo. Roma: Riuniti, 1990, pp. 183-189.

MARX, K. Contribuição à crítica da economia política. São Paulo: Martins Fontes, 1983.

MÉSZÁROS, I. O poder da ideologia. São Paulo: Boitempo, 2004.

NETTO, J. P. "Notas sobre a reestruturação do Estado e a emergência de novas formas de participação da sociedade civil". In: Ivanete Boschetti et al. (orgs.). Política Social: alternativas ao neoliberalismo. UnB: Brasília, 2004.

SEMERARO, G. Gramsci e os novos embates da filosofia da práxis. São Paulo: Ideias\&letras, 2006.

SERRA, R. M. A prática institucionalizada do serviço social: determinações e possibilidades. São Paulo: Cortez, 1982.

SCHIRRU, G. Filosofia da linguagem e filosofia da práxis. AGGIO, A; HENRIQUES, L. S. e VACCA, G. (orgs.). Gramsci no seu tempo. Rio de Janeiro: Contraponto, 2010.

SIMIONATTO, I. Gramsci, sua teoria. Influência no Brasil, incidência no Serviço Social. 3 ed. São Paulo/Florianópolis: Cortez/UFSC, 1995.

"A cultura do capitalismo globalizado. novos consensos e novas subalternidades". In: COUTINHO, C. N. e TEIXEIRA, A de P (orgs.). Ler Gramsci, entender a realidade. Rio de Janeiro: Civilização Brasileira, 2003, pp. 275-290.

TOSEL, A. per una rivalutazione del momento ético-politico e della filosofia della prassi. In: BADALONI, N. et al. (org.). Gramsci e il marxismo contemporaneo. Roma: Riuniti, 1990, pp. 69-90.

Recebido em 26 de novembro de 2010

Aceito para publicação em 14 de março de 2011

EM PAUTA, Rio de Janeiro (RJ), v. 9, n. 27, p. 17-33, Jul. 2011 